\title{
Approach for the analysis of TES technologies aiming towards a circular economy: case study of building-like cubicles
}

\author{
Dieter Boer ${ }^{1}$, Mercè Segarra ${ }^{2, *}$, A. Inés Fernández ${ }^{2}$, Manel Vallès ${ }^{1}$, Carles Mateu$^{3}$, \\ Luisa F. Cabeza ${ }^{3}$ \\ ${ }^{1}$ Departament d’Enginyeria Mecanica, Universitat Rovira i Virgili, Av. Paisos Catalans, 26, 43007- \\ Tarragona, Spain. \\ ${ }^{2}$ DIOPMA Centre, Department of Materials Science \& Physical Chemistry, Universitat de Barcelona, \\ Martí i Franquès, 1, 08028-Barcelona, Spain. \\ ${ }^{3}$ GREiA Research Group, INSPIRES Research Centre, Universitat de Lleida, Pere de Cabrera s/n, 25001- \\ Lleida, Spain \\ *Corresponding author e-mail: m.segarra@ub.edu
}

\begin{abstract}
The objective of this study is to establish an initial framework to evaluate and improve the sustainability of technologies integrating thermal energy storage with the aim to come closer to a circular economy. This is applied to a case study for a building-like cubicle, that includes different options of phase change materials. For the construction of a cubicle, materials can come from ores and feedstock or either recycled feedstock. In order to decrease the impact of materials and approach to a circular economy, the recycled content of materials at start of life should be as high as possible, thus decreasing the amount coming from natural resources. This recycled fraction in current supply depends on the available technologies for reintroducing the recycled materials in the production processes, together with virgin materials coming from primary sources.
\end{abstract}

Results of this analysis show that the decrease of the environmental impact of recycling at the end of life is not so significant as the use of recycled materials at the start of life of the product.

Thus, reuse and recycling of materials and components must be integrated into the initial design in order to come closer to the concept of circular economy.

Keywords: circular economy, life cycle assessment, Recipe, recycling, thermal energy storage

\section{Introduction}

The Energy Conservation and Energy Storage Technical Collaboration Program (TCP) of the International Energy Agency (IEA) [1] states that storage technologies are a central component in energy-efficient systems. Moreover, it highlights that energy storage is a cross-cutting issue, needed of expert knowledge from many disciplines. From the point of view of applications, the energy supply and all end-use sectors need energy storage; from the point of view of technical disciplines, engineering, materials, architecture, and other disciplines are needed. Moreover, the Paris Climate Conference [2] agreed upon GHG-emission reduction targets that may only be achieved with a global energy system, where energy storage is a key technology.

According to the IEA energy storage roadmap [3], energy storage is divided basically in electric energy storage (EES), which includes pumped hydropower, hydrogen batteries, adiabatic compressed air, flywheels, stationary lithium-ion batteries, and redox flow batteries; and thermal energy storage (TES), including technologies such as underground TES (aquifer and borehole 
TES), water storage, latent heat storage, sorption storage, and storage using chemical reactions. Although EES attracted a lot of attention due to the advances in batteries, the importance of TES was also highlighted, with a potential for $\mathrm{CO}_{2}$ emissions reduction estimated to be $2.6 \mathrm{Gt}$ [4].

TES has grown in interest not only at the political level [5][6][7], but also at scientific level. A recent study from Calderon et al. [8] showed that in the last 20 years, TES publications grew from around 150 in 1998 to nearly 2000 in 2016. But most research addresses technical aspects of TES (new materials, new enhancement technologies, new applications, new control systems, etc.).

An environmental approach of TES research is the use of waste and by-product materials as TES materials [9]. Moreover, a few LCA studies on the topic have been published: only 26 documents can be found in Scopus. A recent review on one of the technologies (phase change materials, PCM) is that from Kyriaki et al. [10]; and some of these also include multi-criteria analysis [11][12] or a techno-economic analysis. But none of them take into account a more global approach to TES design.

LCA can be used to assess the environmental impacts of these systems, but a full LCA uses to be quite complex and time-consuming. A first approach to overcome these issues is a streamlined LCA [13][14] which is defined as a shortened form of LCA that may use simplified analytical methods. Another approach is the project PROSUITE (Development and application of standardized methodology for the PROspective SUstaInability assessment of TEchnologies" [15]). It addresses the need for new methods that can measure, analyze and assess new technologies and that takes into account all activities and their effects on the economy, environment and society. They propose a sustainability assessment based on five pillars: Impact on (1) Human Health, (2) Social Well-being, (3) Prosperity, (4) Natural Environment, and (5) Impact on Exhaustible Resources. Nevertheless, these methodologies still have not been used to evaluate the sustainability of TES systems.

When talking about sustainability, the main issue is to define the spatial and time scales in which the system will be implemented [16]. In the case of a TES system, the design for the environment is the main objective to accomplish, as it is the design approach to reduce the environmental and human health impact of a product or a system during its lifespan.

Today, as part of the European Commission continuous effort to transform Europe economy into a more sustainable one, a Circular Economy Action Plan is being developed, and its first result is the 2018 Circular Economy Package [17]. The circular economy is the interaction between sustainability, where the value of products, materials, and resources (water, energy, etc.) is considered, and the economy. It is based on the principle of "closing the life cycle" of goods, services, waste, materials, water, and energy [18]. Therefore, TES is included in this new circular economy approach of considering our actions, as energy is part of the concept, but one step further is to consider circular economy principles when developing TES systems or materials. Such principles are eco-design, industrial and territorial ecology, "functionality" economy, second use, reuse, reparation, recycle, and valorisation.

The objective of this study is to establish an initial framework to evaluate and improve the sustainability of technologies integrating thermal energy storage to come closer to a circular economy. This is applied to a case study for a building application.

\section{Methods for measuring sustainability and contribution to the circular economy strategy}

It is generally agreed that LCA is the most complete technique to evaluate the sustainability of any technology, i.e. for assessing all the inputs and outputs of a product, process, or service, the associated wastes, the impacts (human health, and ecological burdens), and interpreting and communicating the results to the assessment throughout the life cycle of the products or processes under review. But conducting an LCA at the beginning of the design process makes little sense as not much has yet been finalized; the relevant information is not yet available. At the end of the 
process, when all the relevant information is available, it still makes little sense as everything is already finalized and hardly anything can be changed [24]. On the other hand, due to the lack of data and the difficulty in quantifying some of the impacts of the LCA, such as social well-being and prosperity, it is worth to start using a simplified approach with few but pertinent indicators. This approach can further become more sophisticated by adding other indicators that could provide complementary but not so relevant information for the purpose of a general overview of sustainability.

The European Environmental Agency recently published a report in which states that circular economy aims to increase resource efficiency but not fully addressing preservation of natural capital and prevention of environmental risks to human health and well-being [19]. In fact, circular economy can be represented as the core of a green economy perspective that widens the focus from waste and material use to ecosystem resilience and human health and well-being (Figure 1).

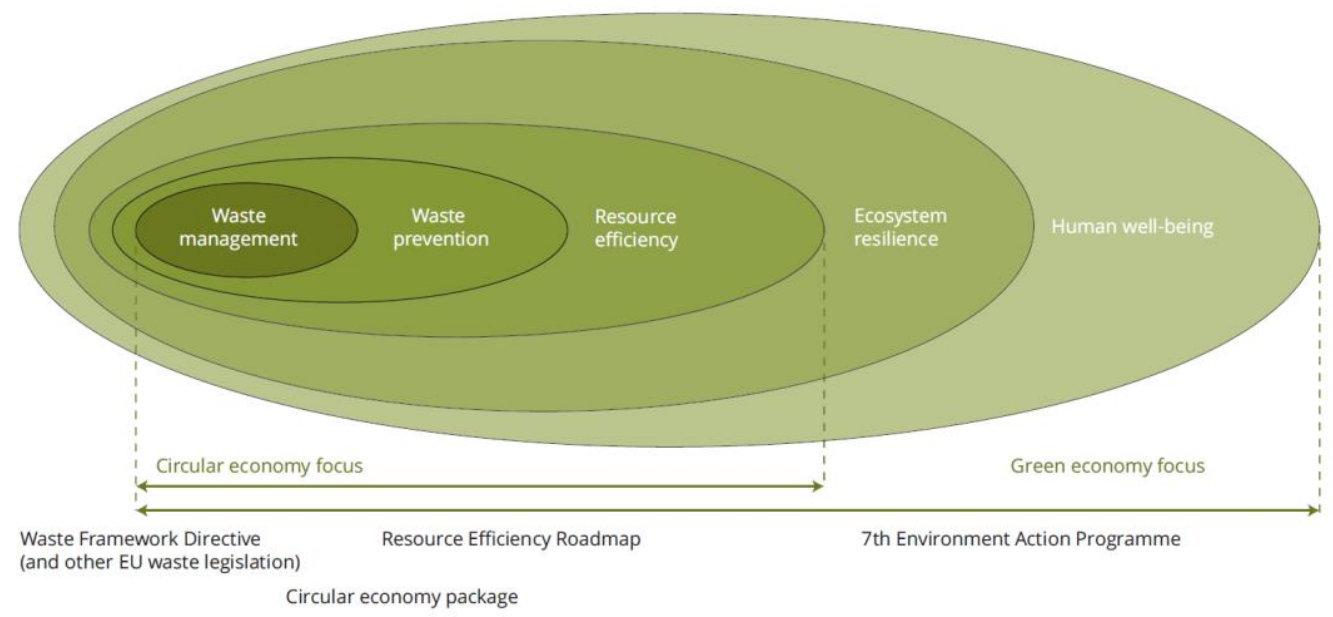

Figure 1. Circular economy and green economy [19].

To monitor progress towards a circular economy, the European Commission has set up a framework consisting of ten indicators grouped in four stages and aspects (Figure 2). 


\section{Circular economy monitoring framework}

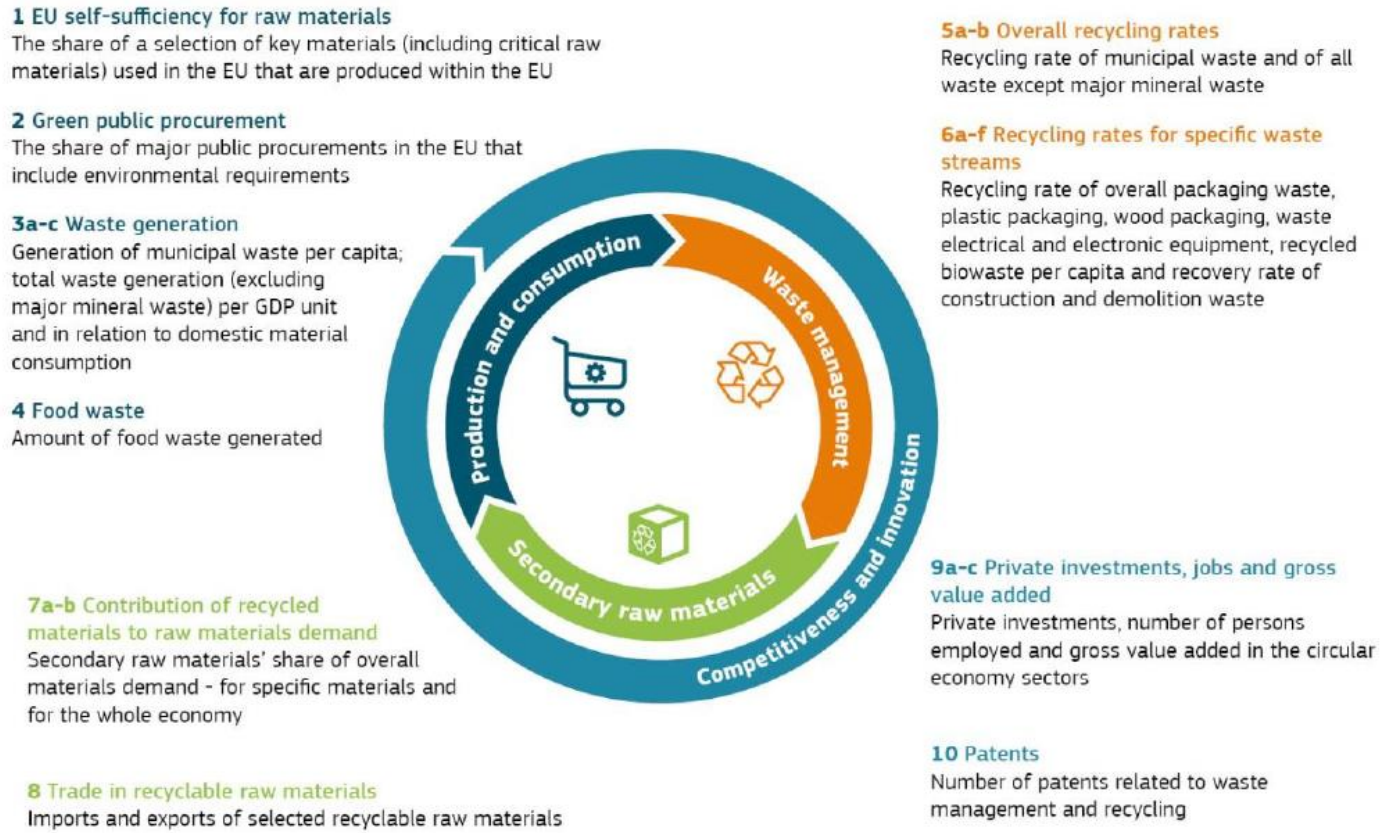

9a-c Private investments, jobs and gross value added

Private investments, number of persons employed and gross value added in the circular economy sectors

10 Patents

Number of patents related to waste management and recycling

Figure 2. Circular monitoring framework set up by the European Commission [20].

Few reviews have been published describing how to measure the effectiveness of the different approaches for assessing circular economy strategies. The most recent is that from Elia [21] in which a summary of the index-based environmental assessment methodologies is made based on the typology of the method and the parameters to be measured.

Table 1. Index-based methodologies for measuring circular economy implementation (adapted from [21]).

\begin{tabular}{|c|c|c|}
\hline Parameter & Single indicator & Multiple indicators \\
\hline \multirow{3}{*}{ Material flow } & Water footprint (WF) & Material flow analysis (MFA) \\
\hline & Materials inputs per unit of service (MIPS) & Substance flow analysis (SFA) \\
\hline & Ecological rucksack (ER) & \\
\hline \multirow{4}{*}{ Energy flow } & Cumulative energy demand (CED) & \\
\hline & Embodied energy (EE) & --- \\
\hline & Emergy analysis (EMA) & \\
\hline & Exergy analysis (EXA) & \\
\hline \multirow{3}{*}{$\begin{array}{l}\text { Land use and } \\
\text { consumption }\end{array}$} & Ecological footprint (EF) & \\
\hline & Sustainable process index (SPI) & --- \\
\hline & Dissipation area index (DAI) & \\
\hline \multirow{3}{*}{$\begin{array}{l}\text { Other life- } \\
\text { cycle based } \\
\text { parameters }\end{array}$} & Carbon footprint (CF) & Life cycle assessment (LCA) \\
\hline & Ecosystem damage potential (EDP) & $\begin{array}{l}\text { Environmental performance strategy map } \\
\text { (EPSM) }\end{array}$ \\
\hline & & Environmental Priority Strategies (EPS) \\
\hline
\end{tabular}


Table 1 shows that current methodologies using single indicators are usually those focused on the study of resources and their depletion (material flow, energy flow, or land use and consumption), while multiple indicators mainly focus on impacts (climate change, ecosystem damages, human health toxicity, etc.). Moreover, LCA is a methodology that can assess both sustainability and contribution to the circular economy.

Circularity can be assessed at different spatial levels using different methods and techniques: macro (national, regional), meso (city, industrial park, supply chain) and micro (company, product). The Ellen MacArthur Foundation and Granta Design have recently developed a metric - and a tool to calculate it - that assesses circularity at product and company level [22]: the Material Circularity Index (MCI), which provides an indication of how much a product materials circulate, ranging from 0 to 1 , in order to allow companies to understand how far they are on the transition from 'linear' to 'circular'. Other attempts have been made to assess circularity at a product level, such as Cradle to Cradle (C2C) certification framework [23] by Cradle-to-Cradle Products Innovation Institute, or the Remanufacturing Product Profile $\left(\mathrm{REPRO}^{2}\right)$ by Gehin et al. [24]. Also, the Eco-costs Value Ratio (EVR), a metric for products based on LCA has been created [25], although it has a low construct validity as it does not specifically address circularity. The Circular Economy Index (CEI) is a more applicable metric [26], but it only focuses on recycling process efficiency.

\section{Evaluation of sustainability and circularity in thermal energy storage systems}

For the evaluation of the environmental impact, the general methodology of analysis of life cycle (LCA) can be followed using Standard databases (EcoInvent, Gabi, OpenLCA). Approaches as ReCiPe [27] can be used for life cycle impact assessment (LCIA), which translates emissions and resource extractions into a limited number of environmental impact scores by means of so-called characterization factors, and that has been developed from the EcoIndicator and CML.

In order to minimize the environmental impact of TES technologies objectives such as performance, reliability, quality, and cost should be balanced. Because the actors in the design, development and implementation of TES technologies are energy and materials flows, the proposed indicators should be based on them.

Furthermore, to assess how well TES technologies perform in the context of a circular economy, new circularity indicators should be considered. In the case of materials, the Material Circularity Indicator [22] can measure how restorative the material flows of a product or company are. Additional impacts and risks come into account when this indicator is complemented by other circularity ones, such as material price variation, material supply chain risks, material scarcity and toxicity, energy usage, and $\mathrm{CO}_{2}$ emissions.

The first stage to start with the evaluation of the environmental impact and the effectiveness of TES technologies on circular economy is to identify the most relevant properties/parameters of materials and system with direct implication on the TES system sustainability. Performance parameters or indicators (PI) described by Palomba et al. [28] is a first study about relevant parameters to be considered which are very useful to characterize the system in a diverse range of aspects such as sustainability. Yet more information is needed to evaluate the contribution of TES to circular economy completely. This could come from the calculation of MCI. For this purpose, a detailed inventory of materials for the technology is needed which will depend on the TES technology studied. 


\section{Methodology}

The methodology applied includes, in this first approach towards circular economy, the life cycle assessment that considers different options for the recycling, including the use of recycled material instead of virgin feedstock.

\section{Life cycle assessment}

Life cycle assessment (LCA) quantifies the potential environmental impacts of goods and processes during their life cycle [29][30]. An LCA study consists of four main phases: goal and scope definition, life cycle inventory, impact assessment, and interpretation. A detailed description is provided by the ISO 14044 standards [29]. Several databases for impact data are available, being the most popular Ecoinvent [31]. In the goal and scope, the definition of the system to study, its boundaries, and the functional unit are established.

In the life cycle inventory analysis (LCI) the inputs and outputs (mass and energy) of the system are quantified. The inventory can be defined as follows:

$$
L C I_{i}^{T O T}=\sum_{j} L C I_{i, j} \forall i
$$

where LCITTOT is the total LCI entry corresponding to the elementary flow $\mathrm{i}$ which is computed as the summation of all the flows $i$ for all the system units $\mathrm{j}$.

The life cycle impact assessment (LCIA) converts the LCI data into impact indicators. Several methodologies exist. In this work, we followed the recommendations of the EU Commission [32] (use of the ReCiPe methodology [27]). First, the LCI data are converted into impacts:

$$
I M P_{e}=\sum_{i} \theta_{e i} L C I_{i}^{T O T} \forall e
$$

where $\theta_{e i}$ is the characterization factor. It connects the elementary flow $i$ with endpoint impact category $e . I M P_{e}$ is the indicator result for endpoint impact category $e$. If we aggregate further, we obtain three damage categories: human health, ecosystems and resources. Each damage category is a combination of different endpoint impacts:

$$
D A M_{d}=\sum_{e \in I D_{d}} I M P_{e} \forall e
$$

$I D_{d}$ indicates the set of endpoint impacts $e$ contributing to damage $d . D A M_{d}$ is the indicator result for damage category $d$. The ReCiPe methodology incorporates three different time perspectives [27]. Here we employ the most commonly used Hierarchist method. In the end, the damages are normalized and aggregated into a single final score ( $\mathrm{RCP})$ :

$$
R C P=\sum_{d} \delta_{d} \xi_{d} D A M_{d}
$$

$R C P$ is the ReCiPe aggregated metric. $\delta_{d}$ and $\xi_{d}$ are the normalization and weighting factors, respectively. Conclusions from the final interpretation phase provide recommendations for improvement. It enables the decision-makers to identify weak aspects of the process where the environmental impact can be improved.

\section{Case study}

The approach developed in this paper is illustrated with an application to building-like cubicles of an experimental installation in Puigverd de Lleida (Spain). Each cubicle has the same geometry with five plain walls of $2.4 \mathrm{~m} \times 2.4 \mathrm{~m}$. Details are given in [33]. As phase change material alternatively paraffin (PCM1) or salt hydrate (PCM2) are used. In that previous paper, also a life cycle assessment was presented, yet without including the option of recycling or reuse of materials. In this study we retake this analysis, update the references for the materials with the 
databases from Ecoinvent [34] and the CES Selector 2018 [35]. The life cycle inventory as a starting point for further analysis is given in Table 2.

Table 2. Inventory data and reference for materials.

\begin{tabular}{|l|l|c|}
\hline Component & Reference material CES Selector2018 & Mass used (kg) \\
\hline brick & brick common hard & 5456 \\
\hline base plaster & plaster of Paris & 518 \\
\hline cement mortar & ordinary Portland & 608 \\
\hline steel bars & AISI 1020 (same for all low carbon) & 262 \\
\hline concrete & normal (Portland cement) & 1240 \\
\hline in floor bricks & brick common hard & 1770 \\
\hline asphalt & asphalt concrete & 153 \\
\hline polyurethane on roofs & polyurethane foam & 9 \\
\hline polyurethane on walls & polyurethane foam & 63 \\
\hline aluminium & $1050 A$, O (building components) & 61 \\
\hline paraffin (PCM1) & --- & 99 \\
\hline salt hydrate (PCM2) & --- & 99 \\
\hline
\end{tabular}

For the construction of a cubicle, materials can come from primary (virgin) materials created from ores and feedstock or either recycled feedstock. In order to decrease the impact of materials and approach to a circular economy, the recycled content of the material at start of life (R) should be as high as possible, thus decreasing the amount of materials coming from natural resources (1-R). This recycled fraction in current supply $(\mathrm{R})$ depends on the available technologies for reintroducing the recycled materials in the production processes, together with virgin materials coming from primary sources, in a sense that the final properties of the obtained product remain as if it was obtained from only virgin materials. The values for $\mathrm{R}$ are not exact and can be approximated as a range and are different for each material [35]. After dismantling the cubicle, at the end of its life (EoL), part of the materials can be recycled ( $\mathrm{r}$ fraction), thus returning to recycled feedstock, and the rest (1-r) goes to disposal. In this case, $r$ should also be as high as possible, and its limit depends on the capacity of sorting the different materials from dismantling the product and reintroduce them into market. Figure 3 illustrates these materials flows.

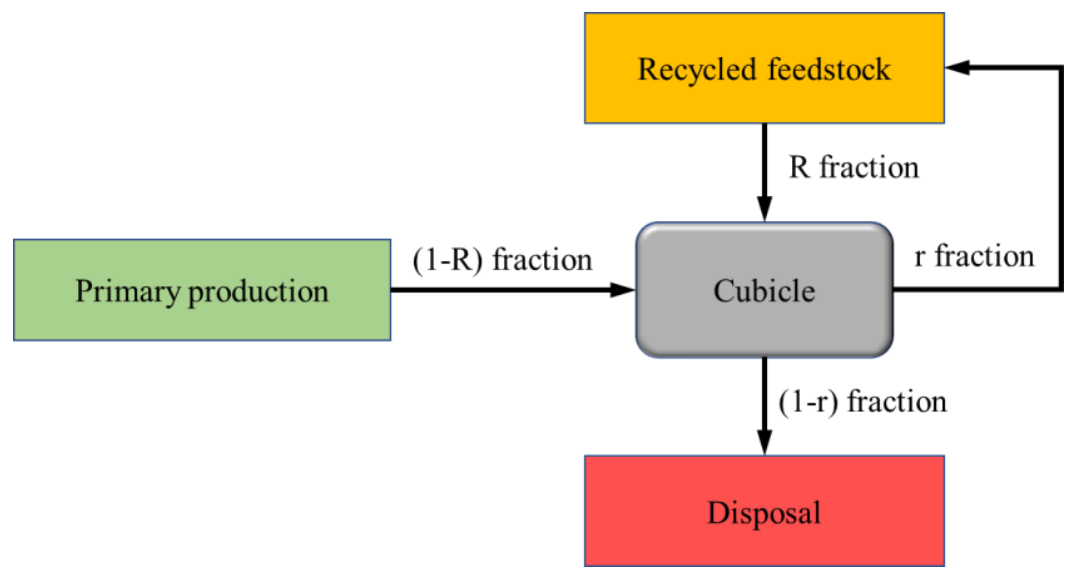

Figure 3. Materials flows in the case study.

Therefore, three scenarios have been considered in this study:

Scenario \#1: All materials for building the cubicle come from primary (virgin) sources $(R=0)$ and go to disposal (landfill) after dismantling the cubicle ( $\mathrm{r}=0)$, corresponding to a fully linear economy approach. 
Scenario \#2: All materials for building the cubicle come from primary (virgin) sources $(R=0)$ and after dismantling the cubicle a fraction goes to recycling processes ( $\mathrm{r}$ ) and the rest (1-r) goes to disposal (landfill).

Scenario \#3: Part of materials used come from recycling (R) and the rest (1-R) from primary sources, and after dismantling the cubicle a fraction goes to recycling processes (r) and the rest (1-r) goes to disposal (landfill).

Table 3 shows the values for $\mathrm{R}$ and $\mathrm{r}$ considered for impact calculations. For Scenario \#3, the maximum values of $\mathrm{R}$ have been considered.

Table 3. Available values for fraction in current supply $(\mathrm{R})$ and recycled fraction $(\mathrm{r})$ at the EoL.

\begin{tabular}{|l|c|c|c|c|}
\hline \multirow{2}{*}{ Material } & \multicolumn{2}{c|}{$\begin{array}{c}\text { Recycled fraction in } \\
\text { current supply (R) }\end{array}$} & $\begin{array}{c}\text { Recycled fraction } \\
\text { at EoL (r) [36] }\end{array}$ \\
\hline brick & $16.50 \%$ & - & $18.20 \%$ & $95.00 \%$ \\
\hline plaster & $0.10 \%$ & - & $0.10 \%$ & $0.10 \%$ \\
\hline cement mortar & $1.14 \%$ & - & $1.26 \%$ & $1.26 \%$ \\
\hline concrete, beams and slabs & $13.00 \%$ & - & $14.40 \%$ & $90.00 \%$ \\
\hline reinforcement steel, beams and slabs & $39.90 \%$ & - & $44.00 \%$ & $90.00 \%$ \\
\hline in-floor concrete bricks & $13.00 \%$ & - & $14.40 \%$ & $95.00 \%$ \\
\hline asphalt & $0.00 \%$ & - & $0.00 \%$ & $0.00 \%$ \\
\hline polyurethane foam & $0.95 \%$ & - & $1.05 \%$ & $1.05 \%$ \\
\hline aluminium sheet & $52.30 \%$ & - & $57.80 \%$ & $95.00 \%$ \\
\hline paraffin (PCM1) & $0.00 \%$ & - & $0.00 \%$ & $0.00 \%$ \\
\hline salt hydrate (PCM2) & $0.00 \%$ & - & $0.00 \%$ & $0.00 \%$ \\
\hline
\end{tabular}

\section{Results}

From the Ecoinvent database (version 3.5) the specific impact of each material in points per $\mathrm{kg}$ is obtained and are presented in Table 4.

Table 4. Specific impact (per kg) of materials for virgin and recycled feedstock. No data is available for recycled PCMs (paraffin and salt hydrate).

\begin{tabular}{|l|c|c|}
\hline \multirow{2}{*}{ Material } & \multicolumn{2}{|c|}{ Specific impact } \\
\cline { 2 - 3 } & Virgin feedstock & Recycled feedstock \\
\hline brick & 0.0328 & 0.0023 \\
\hline plaster & 0.0226 & 0.0022 \\
\hline cement mortar & 0.0267 & 0.0030 \\
\hline concrete, beams and slabs & 0.0083 & 0.0024 \\
\hline reinforcement steel, beams and slabs & 0.5147 & 0.0081 \\
\hline in-floor concrete bricks & 0.0105 & 0.0023 \\
\hline asphalt & 0.0608 & 0.0024 \\
\hline polyurethane foam & 0.6908 & 0.0452 \\
\hline aluminium sheet & 1.9572 & 0.0055 \\
\hline paraffin & 0.2498 & n.d. \\
\hline salt hydrate & 0.0580 & n.d. \\
\hline
\end{tabular}

The difference between both data can be observed in Figure 4 (ordinate in logarithm scale). 


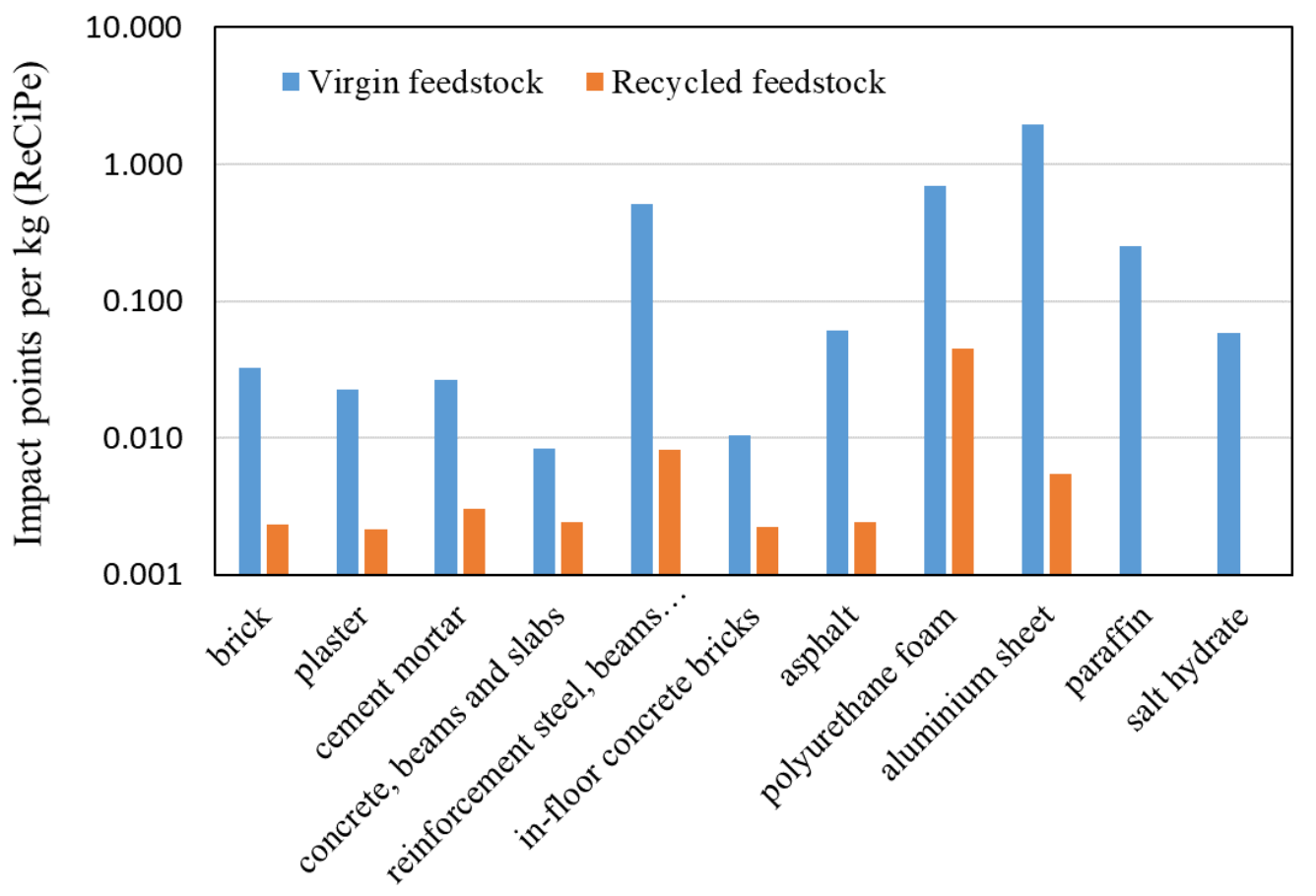

Figure 4. Specific impact of the raw materials (material market in the Ecoinvent database).

Figure 4 shows that the highest impact from the raw materials used in the studied system comes from aluminum, polyurethane, steel, and paraffin, and that salt hydrates have a lower impact than paraffin. This is mainly due to the energy requirements in the production processes.

As it can be observed, the impact of each material is drastically reduced when recycled materials are used in current supply, although the highest impacts are still those for polyurethane, steel, and aluminium. No data on recycling PCMs can be found so they can not be evaluated. Whereas some of the materials in the inventory have lower impacts, the amount used in the system could be high enough to overcome the contribution of those ones.

If the specific impact is multiplied by the mass, the total impact for the different materials and life cycle stages can be calculated using ReCiPe as indicator. The recycled fraction is considered at this stage of the work for the stages of the end of life (disposal and recycling). The details are given in Table 5. 
Table 5. Life cycle impact assessment for the different scenarios.

\begin{tabular}{|c|c|c|c|c|c|c|c|c|c|}
\hline \multirow[t]{2}{*}{ Material } & \multirow[t]{2}{*}{ Lifecycle stage } & \multirow{2}{*}{$\begin{array}{c}\text { Inventory } \\
\text { (kg) }\end{array}$} & \multirow{2}{*}{$\begin{array}{c}\text { Recipe } \\
\text { (H,A) } \\
\text { (V3.5) }\end{array}$} & \multicolumn{2}{|c|}{$\begin{array}{l}\text { Recycled fraction } \\
\text { in current supply }\end{array}$} & \multirow{2}{*}{\begin{tabular}{|c|} 
Recycling \\
$r$ \\
\end{tabular}} & \multicolumn{3}{|c|}{$\begin{array}{l}\text { ReCiPe impact } \\
\text { points Scenario }\end{array}$} \\
\hline & & & & Rmin & Rmax & & $\# 1$ & $\# 2$ & $\# 3$ \\
\hline \multirow{3}{*}{ brick } & material market & 5456 & 0.033 & \multirow{3}{*}{$16.50 \%$} & \multirow{3}{*}{$18.20 \%$} & \multirow{3}{*}{$95.00 \%$} & 178.9 & 178.9 & \begin{tabular}{|l|}
146.4 \\
\end{tabular} \\
\hline & recycled waste market & & 0.002 & & & & \begin{tabular}{|l|}
0.0 \\
\end{tabular} & 0.0 & 2.3 \\
\hline & waste final disposal & & 0.002 & & & & 11.5 & 0.6 & 0.6 \\
\hline \multirow{3}{*}{ plaster } & material market & 518 & 0.023 & \multirow{3}{*}{$0.10 \%$} & \multirow{3}{*}{$0.10 \%$} & \multirow{3}{*}{$0.10 \%$} & 11.7 & 11.7 & 11.7 \\
\hline & recycled waste market & & 0.002 & & & & 0.0 & 0.0 & 0.0 \\
\hline & waste final disposal & & 0.002 & & & & 0.9 & 0.9 & 0.9 \\
\hline \multirow{3}{*}{ cement mortar } & material market & 608 & 0.027 & \multirow{3}{*}{$1.14 \%$} & \multirow{3}{*}{$1.26 \%$} & \multirow{3}{*}{$1.14 \%$} & 16.2 & 16.2 & 16.0 \\
\hline & recycled waste market & & 0.003 & & & & 0.0 & 0.0 & 0.0 \\
\hline & waste final disposal & & 0.002 & & & & 1.3 & 1.3 & 1.3 \\
\hline \multirow{3}{*}{$\begin{array}{l}\text { concrete, beams } \\
\text { and slabs }\end{array}$} & material market & 1240 & 0.008 & \multirow{3}{*}{$13.00 \%$} & \multirow{3}{*}{$14.40 \%$} & \multirow{3}{*}{$90.00 \%$} & 10.3 & 10.3 & 8.8 \\
\hline & recycled waste market & & 0.002 & & & & 0.0 & 0.0 & 0.4 \\
\hline & waste final disposal & & 0.002 & & & & 3.0 & 0.3 & 0.3 \\
\hline \multirow{3}{*}{$\begin{array}{l}\text { reinforcement } \\
\text { steel, beams and } \\
\text { slabs }\end{array}$} & material market & 262 & 0.515 & \multirow{3}{*}{$39.90 \%$} & \multirow{3}{*}{$44.00 \%$} & & 134.8 & 134.8 & 75.5 \\
\hline & recycled waste market & & 0.008 & & & $90.00 \%$ & \begin{tabular}{|l|}
0.0 \\
\end{tabular} & 0.0 & 0.9 \\
\hline & waste final disposal & & 0.008 & & & & 2.0 & 0.2 & 0.2 \\
\hline & material market & 1770 & 0.011 & & & & 18.6 & 18.6 & 16.0 \\
\hline in-floor concrete & recycled waste market & & 0.002 & $13.00 \%$ & $14.40 \%$ & $95.00 \%$ & 0.0 & 0.0 & 0.6 \\
\hline & waste final disposal & & 0.002 & & & & 3.9 & 0.2 & 0.2 \\
\hline & material market & 153 & 0.061 & & & & 9.3 & 9.3 & 9.3 \\
\hline asphalt & recycled waste market & & 0.002 & $0.00 \%$ & $0.00 \%$ & $0.00 \%$ & 0.0 & 0.0 & 0.0 \\
\hline & waste final disposal & & 0.002 & & & & 0.3 & 0.3 & 0.3 \\
\hline & material market & 72 & 0.691 & & & & 49.7 & 49.7 & 49.2 \\
\hline polyurethane & recycled waste market & & 0.045 & $0.95 \%$ & $1.05 \%$ & $0.95 \%$ & 0.0 & 0.0 & 0.0 \\
\hline & waste final disposal & & 0.045 & & & & 3.3 & 3.2 & 3.2 \\
\hline & material market & 61 & 1.957 & & & & 119.4 & 119.4 & 50.4 \\
\hline aluminium sheet & recycled waste market & & 0.005 & $52.30 \%$ & $57.80 \%$ & $95.00 \%$ & \begin{tabular}{|l|}
0.0 \\
\end{tabular} & 0.0 & 0.2 \\
\hline & waste final disposal & & 0.005 & & & & 0.3 & 0.0 & 0.0 \\
\hline & material market & 99 & 0.250 & & & & 24.7 & 24.7 & 24.7 \\
\hline paraffin & recycled waste market & & 0.000 & $0.00 \%$ & $0.00 \%$ & $0.00 \%$ & 0.0 & 0.0 & 0.0 \\
\hline & waste final disposal & & 0.015 & & & & 1.5 & 1.5 & 1.5 \\
\hline & material market & 99 & 0.058 & & & & 5.7 & 5.7 & 5.7 \\
\hline salt hydrate & recycled waste market & & 0.000 & $0.00 \%$ & $0.00 \%$ & $0.00 \%$ & 0.0 & 0.0 & 0.0 \\
\hline & waste final disposal & & 0.008 & & & & 0.8 & 0.8 & 0.8 \\
\hline & & & & & Tota & al paraffin & \begin{tabular}{|l|}
601.8 \\
\end{tabular} & 582.3 & 421.0 \\
\hline & & & & & Total sal & alt hydrate & 582.1 & 562.6 & 401.4 \\
\hline
\end{tabular}

The impact for the two extreme scenarios is analysed, that is a linear economy approach (\#1, all virgin materials and no recycling at EoL) and a circular economy approach (\#3, including the maximum recycled materials in current supply and recycling at EoL). It can be seen that about $30 \%$ of the overall impact (from 602 to $421 \mathrm{ReCiPe}$ points for paraffin and from 582 to 401 for salt hydrate) can be reduced, mainly to the impact reduction of raw materials (Figure 5). On the other hand, another impact reduction is due to the increase of recycling and therefore a decrease in material disposal. 


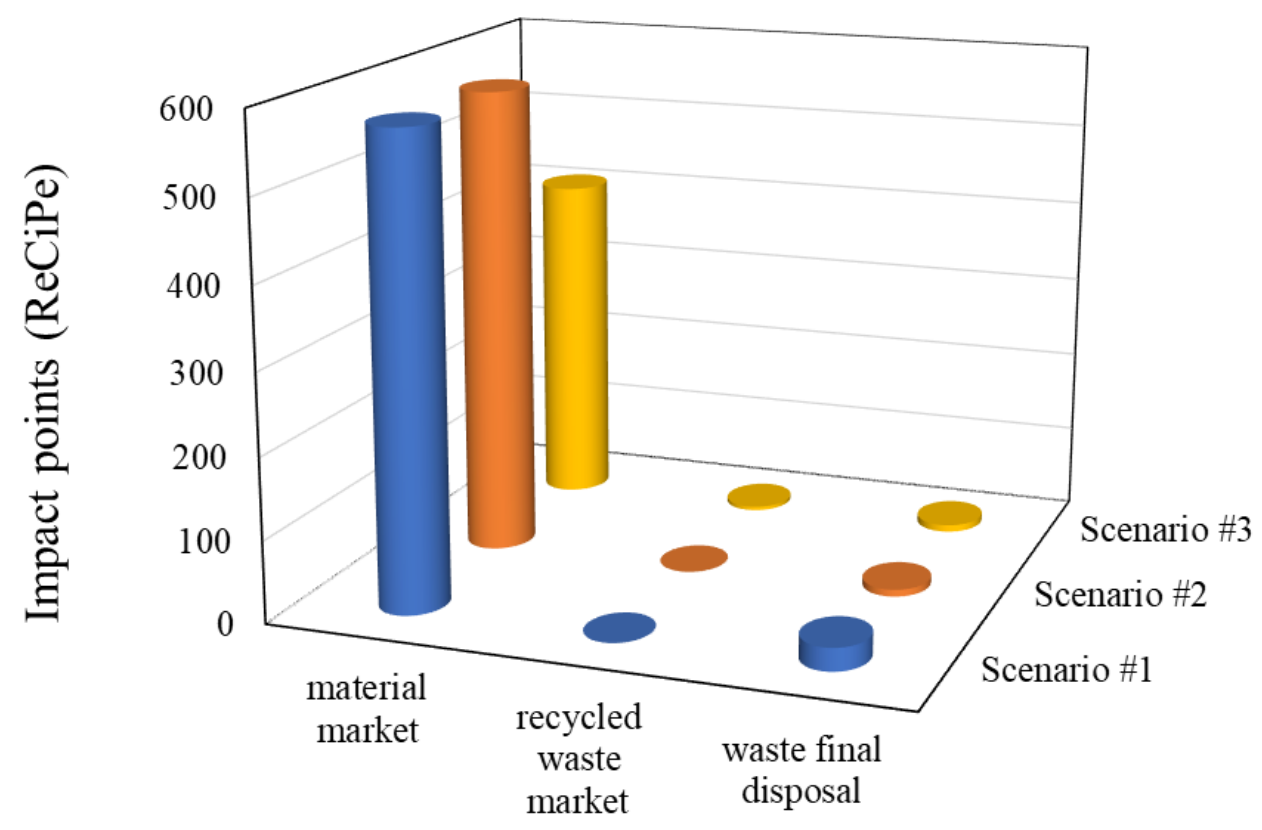

Figure 5. Comparison of the impact at the different lifecycle stages for each studied scenario (paraffin case).

As can be seen in Figure 5, the contribution to the decrease of environmental impact of recycling at the EoL (which is reflected in the stage of waste final disposal) is not so significant as the use of recycled materials in the start of life of the product (reflected in the stage of material market). This leads to the need for developing new processes to include higher amounts of recycled feedstock to current production in order to decrease the reduction of natural resources.

Considering the high relevance of the raw material, Figure 6 presents the impact of the different materials for the three studied scenarios and using paraffin. Besides the materials with high specific impact (Al, steel, PU and paraffin) brick has now an important role due to the high mass used. Regarding phase change materials, the impact of salt hydrates is significantly lower than the one from paraffin.

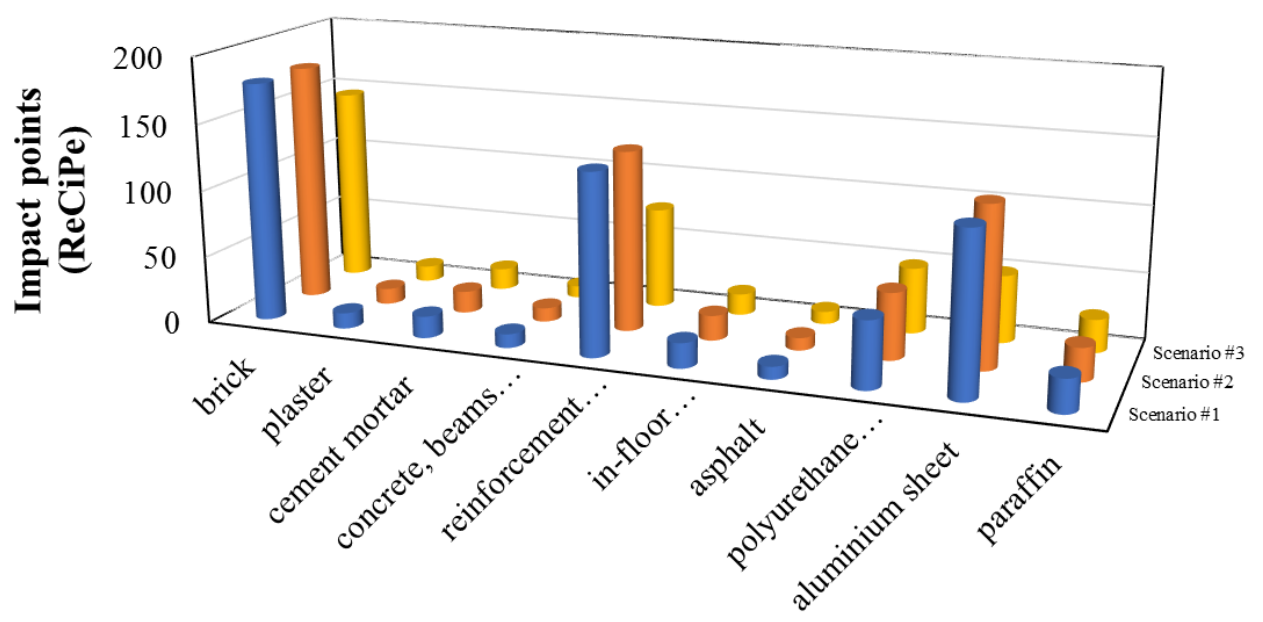

Figure 6. Total impact considering only the raw material (material market in the Ecoinvent database). 
Finally, Figure 7 shows the contribution of the different materials including all life cycle stages for the two extreme scenarios. The results are presented for paraffin and for salt hydrate as phase change material. If the overall impact must be reduced, different approaches should be carried out: use materials with a low impact (mineral salts instead of paraffin), reduction of the mass used (especially in materials with a high contribution as bricks), increase the amount of recycled fraction in materials supply (increase R), and increase the recycling (increase r), especially of the materials with a high specific impact (per kg).
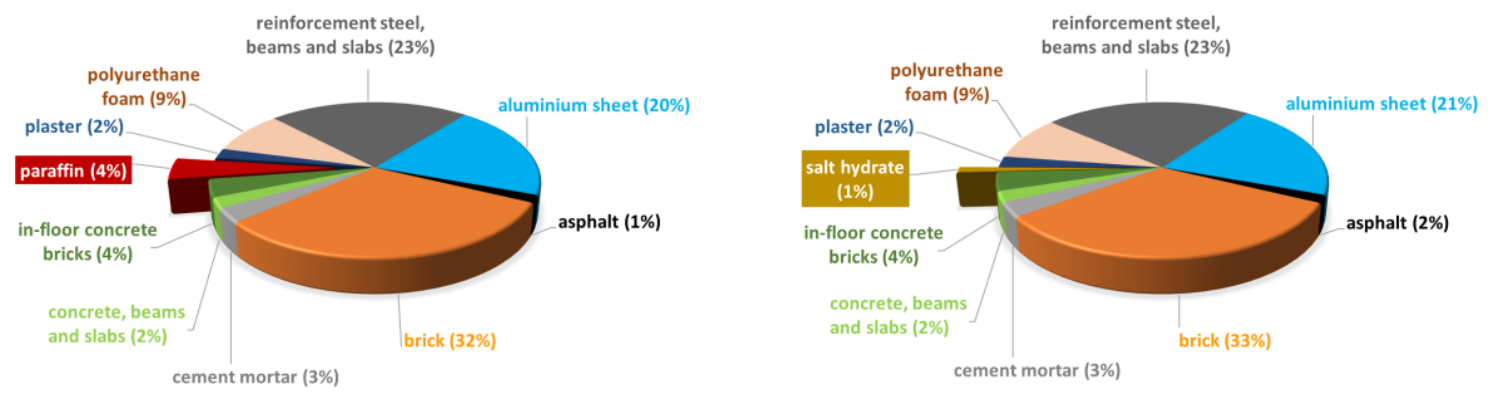

SCENARIO \#1

SCENARIO \#1
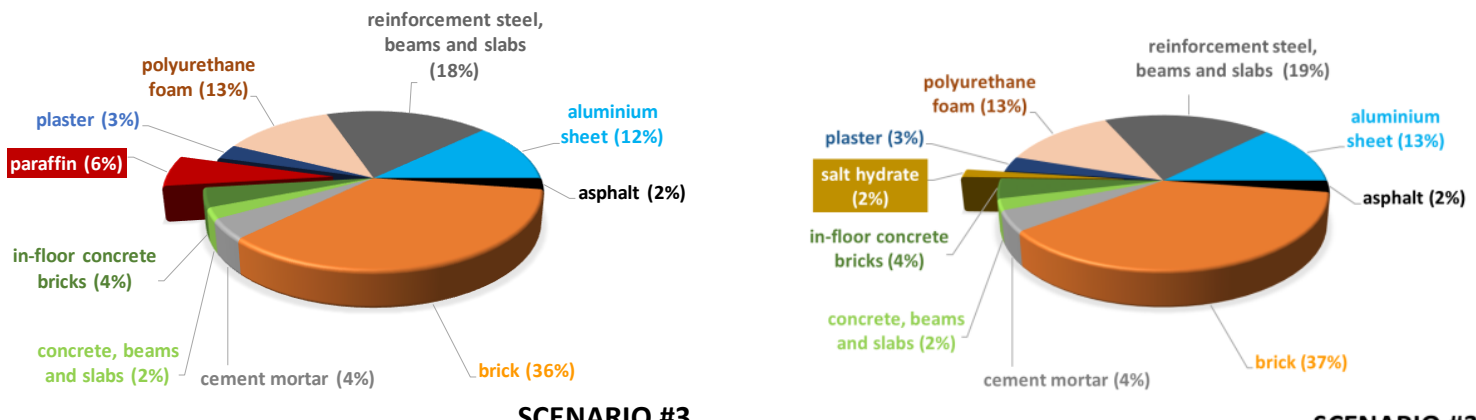

SCENARIO \#3

SCENARIO \#3

a) Paraffin

b) Salt hydrate

Figure 7. Contribution of the materials to the environmental impact in each scenario.

For those materials whose recycled fraction in current supply is significant (such as steel and aluminium), the use of this recycled fraction instead of virgin material makes their contribution to the total environmental impact to decrease substantially. Meanwhile, those materials with no recycled feedstock slightly increase their contribution.

The biggest potential for the reduction of the overall impact can be expected from a reduction of the impact of the virgin raw material. Crucial points here are the reuse and the recycling of materials and components. These aspects must already be integrated into the initial design in order to come closer to the concept of circular economy.

\section{Conclusions}

Although a lot of work has been done on the evaluation of the sustainability of products and technologies, circular economy is a relatively new concept, and thus its implementation is still in early stages. There is a big interest regarding the contribution of new technologies to circular economy. One of the main drawbacks is the lack of agreement on how to measure it. Different 
methodologies have been proposed and a framework to monitor progress towards a circular economy has already been set up by the European Commission, but there is still a long way to go.

The case study evaluated in this paper shows the relevance of the impact of the materials that are used in the construction. Recycling and reuse have the potential to reduce the overall environmental impact. This has to focus especially on materials with a high specific impact. But significant reductions can only be obtained by a consequent integration of recycling and reuse of both components and materials. This has to be considered in a design based on the concepts of the circular economy, which affect all life cycle stages of a product.

Future work will focus on this concept for systems that integrate thermal energy storage. This will include research on materials, components and applications.

\section{Acknowledgements}

The work partially funded by the Spanish government RTI2018-093849-B-C31, RTI2018093849-B-C32, and RTI2018-093849-B-C33 MCIU/AEI/FEDER, UE. The authors would like to thank the Catalan Government for the quality accreditation given to their research group (GREiA - 2017 SGR 1537, DIOPMA - 2017 SGR 118, AGACAPE - 2017 SGR 1409). GREiA and DIOPMA are certified agent TECNIO in the category of technology developers from the Government of Catalonia. This work is partially supported by ICREA under the ICREA Academia programme.

\section{References}

[1] International Energy Agency, No Title, (n.d.). https://iea-eces.org/.

[2] U.F. on C.C. (UNFCCC), No Title, COP21 - 2015 Paris Clim. Conf. (n.d.). http://www.cop21 paris.org/.

[3] International Energy Agency, Technology roadmap: Energy storage, 2014.

[4] P. Arce, M. Medrano, A. Gil, E. Oró, L.F. Cabeza, Overview of thermal energy storage (TES) potential energy savings and climate change mitigation in Spain and Europe, Appl. Energy. 88 (2011) 2764-2774. doi:10.1016/j.apenergy.2011.01.067.

[5] O. Teller, J.-P. Nicolai, M. Lafoz, D. Laing, R. Tamme, Allan Schroder Pedersen Mattias Andersson, C. Folke, C. Bourdil, M. Conte, G. Gigliucci, I. Fastelli, M. Vona, M. Rey Porto, T. Hackensellner, R. Kapp, M.N. Hans Juergen Seifert, Michael Sander, J. Lugaro, Michael Lippert, P. Hall, R. Saliger, A. Harby, M. Pihlatie, N. Omar, Joint EASE/EERA recommendations on an European Energy Research Alliance, n.d. https://www.eeraset.eu/wp-content/uploads/148885-EASE-recommendations-Roadmap-04.pdf.

[6] ESTEA, SET-Plan - SOLAR THERMAL ELECTRICITY EUROPEAN INDUSTRIAL INITIATIVE (STE-EII), $2013.2 \mathrm{http}: / / \mathrm{www}$. solarera.net/files/7613/9083/0789/Implementation_Plan_for_CSP_2013_2015.pdf.

[7] L.F. Cabeza, J.M. Corberan, N. Fevrier, S. Landolina, M. Monsberger, T. Nowak, P. Papillon, W. Sparber, S. Spoelstra, W. van Helden, Cross-Cutting Technology Roadmap, 2014.

[8] A. Calderón, K. Hernández-Valle, C. Barreneche, E. Galindo, M. Segarra, A.I. Fernández, Where is Thermal Energy Storage (TES) research going? - A bibliometric analysis, in: Proc. 14th Int. Conf. Energy Storage - EnerSTOCK2018, Adana, Turkey, 2018: pp. 891898.

[9] A. Gutierrez, L. Miró, A. Gil, J. Rodriguez-Aseguinolaza, C. Barreneche, N. Calvet, X. Py, A.I. Fernandez, M. Grágeda, S. Ushak, L.F. Cabeza, Advances in the valorization of waste and by-product materials as thermal energy storage (TES) materials, Renew. Sustain. Energy Rev. 59 (2016) 763-783.

[10] E. Kyriaki, C. Konstantinidou, E. Giama, A.M. Papadopoulos., Life cycle analysis (LCA) 
and life cycle cost analysis (LCCA) of phase change materials (PCM) for thermal applications: A review, Int. J. Energy Res. 42 (2018) 3068-3077.

[11] V. Tulus, D. Boer, L.F. Cabeza, L. Jiménez, G. Guillén-Gosálbez, Enhanced thermal energy supply via central solar heating plants with seasonal storage: A multi-objective optimization approach, Appl. Energy. 181 (2016) 549-561.

[12] J. Carreras, C. Pozo, D. Boer, G. Guillén-Gosálbez, J.A. Caballero, R. Ruiz-Femenia, L. Jiménez, Systematic approach for the life cycle multi-objective optimization of buildings combining objective reduction and surrogate modeling, Energy Build. 130 (2016) 506518. doi:10.1016/j.enbuild.2016.07.062.

[13] K. Weitz, A. Sharma, B. Vigon, E. Price, G. Norris, P. Eagan, W. Owens, A. Veroutis, Streamlined Life-Cycle Assessment: A Final Report from the SETAC North America Streamlined LCA Workgroup, 1999.

[14] M. Arena, G. Azzone, A. Conte, A streamlined LCA framework to support early decision making in vehicle development, J. Clean. Prod. 41 (2013) 105-113.

[15] PROSUITE: Development and application of standardized methodology for the PROspective SUstaInability assessment of TEchnologies, 2013. https://cordis.europa.eu/project/rcn/92592_en.html.

[16] M.F. Ashby, Materials and sustainable development, Butterwoth-Heinemann Publishing, Oxford, UK, 2016.

[17] European Commission, Circular Economy - Implementation of the Circular Economy Action Plan. http://ec.europa.eu/environment/circular-economy/index_en.htm, (2018). http://ec.europa.eu/environment/circular-economy/index_en.htm.

[18] Economía Circular, Circular Economy, (n.d.). http://economiacircular.org/EN/?page_id=62.

[19] E.E.A. EEA, Circular economy in Europe - Developing the knowledge base, 2016. doi:10.1002/bit.260180112.

[20] EC, Communication on a monitoring framework for the circular economy, 2018. doi:COM/2018/029 final.

[21] V. Elia, M.G. Gnoni, F. Tornese, Measuring circular economy strategies through index methods: A critical analysis, J. Clean. Prod. 142 (2017) 2741-2751. doi:10.1016/j.jclepro.2016.10.196.

[22] Ellen MacArtur Foundation and Granta Design, An Approach to Measuring Circularity, 2015. https://www.ellenmacarthurfoundation.org/resources/apply/circularity-indicators.

[23] Cradle to Cradle Products Innovation Institute, Pilot study - Impacts of the cradle to cradle certified products program, n.d. https://www.c2ccertified.org/impact-study.

[24] A. Gehin, P. Zwolinski, D. Brissaud, A tool to implement sustainable end-of-life strategies in the product development phase, J. Clean. Prod. 16 (2008) 566-576. doi:10.1016/j.jclepro.2007.02.012.

[25] A.E. Scheepens, J.G. Vogtländer, J.C. Brezet, Two life cycle assessment (LCA) based methods to analyse and design complex (regional) circular economy systems. Case: Making water tourism more sustainable, J. Clean. Prod. 114 (2016) 257-268. doi:10.1016/j.jclepro.2015.05.075.

[26] F. Di Maio, P.C. Rem, A Robust Indicator for Promoting Circular Economy through Recycling, J. Environ. Prot. (Irvine,. Calif). 06 (2015) 1095-1104. doi:10.4236/jep.2015.610096.

[27] M. Goedkoop, R. Heijungs, A. De Schryver, J. Struijs, R. van Zelm, ReCiPe 2008. A LCIA method which comprises harmonised category indicators at the midpoint and the endpoint level. Characterisation., A Life Cycle Impact .... (2009) 133. doi:http://www.lcia-recipe.net.

[28] V. Palomba, J. Gasia, J. Romaní, A. Frazzica, L.F. Cabeza, Definition of Performance Indicators for Thermal Energy Storage, in: 2019: pp. 227-242. doi:10.1007/978-3-31996640-3_13.

[29] International Organization for Standardization, The New International Standards for Life Cycle Assessment: ISO 14040 and ISO 14044., Geneva, Switzerland, 2006.

[30] J. Guinée, Handbook on life cycle assessment - Operational guide to the ISO standards, 
Int. J. Life Cycle Assess. 6 (2001) 255. doi:10.1007/BF02978784.

[31] R. Frischknecht, G. Rebitzer, The ecoinvent database system: A comprehensive webbased LCA database, J. Clean. Prod. 13 (2005) 1337-1343. doi:10.1016/j.jclepro.2005.05.002.

[32] M. Hauschild, M. Goedkoop, J. Guinee, R. Heijungs, M. Huijbregts, O. Jolliet, Recommendations for Life Cycle Impact Assessment in the European context - based on existing environmental impact assessment models and factor, in: Int. Ref. Life Cycle Data Syst. - ILCD Handb., 2011. doi:10.278/33030.

[33] A. de Gracia, L. Rincón, A. Castell, M. Jiménez, D. Boer, M. Medrano, L.F. Cabeza, Life Cycle Assessment of the inclusion of phase change materials (PCM) in experimental buildings, Energy Build. 42 (2010) 1517-1523. doi:10.1016/j.enbuild.2010.03.022.

[34] Ecoinvent database version 3.5, (n.d.). https://www.ecoinvent.org.

[35] Granta Design Ltd, CES Selector 2018, (2018).

[36] C. Thormark, Conservation of energy and natural resources by recycling building waste, Resour. Conserv. Recycl. 33 (2001) 113-130. doi:10.1016/S0921-3449(01)00078-7. 